clear. In the run-up to the meeting, Nature said that the event presented an opportunity to take stock, acknowledge past failures and identify opportunities to break political deadlock. It may have succeeded with the first two, but has certainly fallen flat with the all-important third.

The world needs hope, a sustainable goal and a clear path to reach it. It needs a strong message to invigorate the global conversation and to motivate current and future generations of scientists, thinkers and leaders. Right now, politicians need to lay the groundwork and implement productive policies on the ground. They also need to find practical and politically viable ways to scale things up. With a clear aim in view and a workable means to achieve it, political leaders would find it much harder to turn their backs on the problems the world faces.

Perhaps Rio really was a failure, but not for the reasons levelled at the conference over the past week. Put simply, the agreement failed to capture the imagination. The wording does not lay out a clear and compelling vision - a brave new message that will spark debate among friends, family and colleagues. Sadly, it doesn't even capture the spirit and energy that enlivened the conference itself over the past two weeks.

For the more than 45,000 people who attended the conference, the picture was very different. Countless individuals, businesses and nonprofit organizations unveiled their latest ideas to eager audiences. Governments announced initiatives to reduce emissions, protect forests, expand access to energy and generally make the world a cleaner and greener place for all. Visitors from around the world were introduced to global problems - and, in the case of Rio's favelas, smart solutions clarifying the connection between poverty and the need for sustainable development. Millions of Brazilians, at least, were bombarded with news coverage detailing the full suite of issues under discussion. This is not enough, but it is not nothing either. By focusing too much on the final

text and what it contains, critics are ignoring what was there.

Although the agreement that came out of Rio last week did not define sustainable-development goals, it did create a process to do so. These goals will need to be informed by science if they are to be meaningful. And policy-makers will need to find a way to assess whether they are making progress on the social, economic and environmental issues they face. Governments must cope with a dizzying array of interrelated challenges, from freshwater shortages and carbon emissions to issues of food, poverty, biodiversity and demographics. They have limited resources with which to tackle a bewildering portfolio of complex problems, and they need to understand where the environmental boundaries

"The world needs hope, a sustainable goal, and a clear path to reach it." lie when they try to solve them.

At its heart, this is a scientific challenge, and one that scientists and funding agencies have already set out to tackle through the Future Earth initiative, a framework of research into sustainable development paid for by the National Science Foundation. It represents an opportunity to analyse and assess competing uses for various resources across the global landscape. To help translate this useful work into relevant information, scientists must find a way to integrate their knowledge of natural systems with economics and other social sciences, to better assess the solutions that people will be willing to accept and to encourage new technologies and ideas to ripple through society. Speaking in Rio, Hans Joachim Schellnhuber, a physicist by training and director of the Potsdam Institute for Climate Impact Research in Germany, said that the next decade could be "the decade of the social sciences". He may well be right. Just as fear does not sell, it should also be clear by now that simply presenting the bare facts on their own, no matter how starkly, will not be enough.

\title{
Pig out
}

\section{If farmers do not rein in the use of antibiotics for livestock, people will be severely affected.}

\section{$\mathrm{T}$} he spread of dangerous bacteria that are resistant to antibiotics is fuelled by overuse of the drugs - and not just in people. Farmers around the world routinely feed antibiotics to their animals, not only to prevent and treat infections, but also to make their animals grow faster. This leads to drug-resistant bacteria in the animals, and this resistance can spread to the bacteria that infect us.

The overuse of antibiotics in farm animals is a global issue. Human propensity for trade and travel ensures that resistant bacteria spread easily around the world, so as long as any one country pumps its pigs and poultry full of the drugs, everyone is at risk.

In 1998, the Danish poultry industry took the unusual step of volunteering to stop using antibiotics for the promotion of animal growth. Two years later, the country's pork farmers did the same. Denmark might be a small country, but it is the world's largest exporter of pork. And it didn't stop there, writes Frank Aarestrup in a Comment piece on page 465, Denmark went on to reduce its overall use of antibiotics in livestock by $60 \%$. It achieved this by creating a comprehensive surveillance system to monitor overuse, and limiting the amount of money that vets could make from selling the drugs to farmers.

Many feared that the changes would cripple Denmark's pork production. Instead, production rose by $50 \%$. "Any country trying to limit the use of antibiotics in livestock can learn from what my colleagues and I did in Denmark, adjusting what worked to local needs," Aarestrup writes. These are encouraging words, but it is unlikely to be that simple.

The biggest obstacle is likely to be generating the political resolve and public support needed to crack down on the lucrative trade in antibiotics. This was possible in Denmark because there, perhaps uniquely, warnings from the medical community were picked up by the media, creating widespread public awareness of the problems caused by the overuse of antibiotics. People in other countries may not be so engaged, particularly when faced with the inevitable lobbying of the agricultural and veterinary sectors, which make big profits from selling antibiotics.

Also a problem is the fact that in many countries, farmers tend to work independently of each other. Almost all Danish farmers, by contrast, are members of the Danish Agriculture and Food Council, through which they frequently communicate and interact. This meant that they had a convenient forum in which to debate the issue and come to the decision to stop using antibiotics for growth. Denmark also has a detailed system in place to keep track of the effects of antibiotic use by farmers, which helps to enforce the regulations. In the United States, drug companies provide the Food and Drug Administration with data on the quantity of antibiotics sold to farmers, although they do not routinely say what types of animal the drugs are given to, or what the drugs are used for. The nation therefore has the necessary infrastructure and reporting system to monitor and regulate the use of antibiotics for animal growth, should it wish to do so, as do other countries. And the European Union has already banned such drug use.

The first step to building the case for tighter control is to obtain more specific data. Researchers should be able to survey ten farms in ten US states, for example, and extrapolate those data nationally to build up an accurate picture of antibiotic use. The drugs are almost certainly overused, and are almost certainly having a damaging impact on public health, so publishing the results would help in raising aware- $\rightarrow$ NATURE.COM To comment online, click on Editorials at: go.nature.com/xhunqv ness of the problem and generating the necessary support. The people of Denmark deserve praise for their efforts, and other countries, and their people, should look more carefully at what their animals are being fed. 